\title{
Smoking Cessation Considerations for People with Multiple Sclerosis
}

Christa Brooker, PharmD ${ }^{1}$; Myla D. Goldman, MD, MSc ${ }^{2}$; S. Ross Tingen, PharmD, BCPS, MScS ${ }^{2}$

${ }^{1}$ Department of Pharmacy, University of Virginia Health; ${ }^{2}$ Department of Pharmacy and Department of Neurology, Virginia

Commonwealth University Health

\begin{abstract}
Background: Comprehensive care of people with multiple sclerosis integrates disease modifying therapy, symptom management and minimization of risk factors for disease progression. Cigarette smoking is a modifiable risk factor associated with development and progression of disease and increased disability. However, little is known about specific factors that affect smoking cessation in patients with multiple sclerosis or how to integrate smoking cessation into specialized multiple sclerosis care.

Methods: Twenty-nine active smokers with multiple sclerosis were surveyed at the James Q. Miller Multiple Sclerosis clinic at the University of Virginia Health. Demographics, smoking history, multiple sclerosis history, interest in quitting, barriers to quitting and cessation modalities of interest were collected, specifically interest in working with a clinical pharmacist for cessation.

Results: Seventy-six percent of individuals believed that there was no relationship between smoking and MS diagnosis and 52\% were unaware of any relationship between smoking and disease progression. Less than half of patients (41\%) reported receiving counseling from a primary care physician or neurologist about the importance of smoking cessation. Common barriers to quitting included enjoyment of smoking (76\%) and cravings (55\%). Seventy-six percent of patients expressed interest in utilizing pharmacotherapy and $37 \%$ were interested in working closely with a clinical pharmacist.

Conclusions: It is critical that providers caring for patients with multiple sclerosis assess smoking status and educate smokers about the relationship between smoking and disease progression. Efforts should be made to better understand patient-specific barriers to quitting and preferred methods of treatment, including pharmacotherapy and behavioral therapy. A multidisciplinary approach to smoking cessation that includes a clinical pharmacist may aid in the development of individualized care plans with frequent monitoring to improve patient success.
\end{abstract}

Keywords: smoking cessation, multiple sclerosis, nicotine, pharmacist

\section{Introduction}

While multiple sclerosis (MS) remains a complex immunemediated disease, significant advances in research have informed clinical practice and improved our ability to effectively care for this patient population. Recognized risk factors for the development of MS include non-modifiable factors such as age, gender and geographic latitude and modifiable risk factors such as vitamin D level and tobacco use. ${ }^{1,2}$ Caring for a patient with MS requires a comprehensive approach which integrates both disease modifying therapy (DMT) and symptom management. The increased identification and recognition of modifiable risk factors has expanded patient care to include efforts to minimize risk factors, where possible.

The association between cigarette smoking and multiple sclerosis development and progression has become more evident over the last several decades based upon epidemiological data and focused research. A prospective evaluation of women enrolled in the Nurses' Health Studies I and II found that the relative incidence of developing multiple sclerosis was 1.6 among active smokers compared to 1.2 among past smokers. This study also found a significant increase in

Corresponding author: Christa Brooker, PharmD

University of Virginia Health, P.O. Box 800674

Charlottesville, VA 22908-0674

Email: ctb7v@virginia.edu relative incidence rate when accounting for cumulative exposure to cigarette smoking over time. ${ }^{3}$ A meta-analysis conducted by Handel and colleagues in 2011 demonstrated that smokers were nearly 1.5 times more likely to develop MS than non-smokers. ${ }^{4}$ In addition to increasing the risk of developing multiple sclerosis, tobacco use also influences disease progression. Those who smoke will progress to a secondary progressive state of multiple sclerosis at a more rapid rate than non-smokers. Additionally, smokers may experience more severe disability. ${ }^{5}$ Due to its potential to influence disease progression and improve the overall health of the MS population, smoking cessation counseling should be included in all comprehensive care plans.

The James Q. Miller Multiple Sclerosis clinic at the University of Virginia Health (UVaH) cares for nearly 1,500 patients each year. The multiple sclerosis clinic consists of a multidisciplinary team including neurologists, a nurse practitioner, nursing staff, physical and occupational therapists, a pharmacy technician and a clinical pharmacist. The clinical pharmacist plays an integral role in providing access to disease-modifying therapy, ongoing monitoring, patient education and symptomatic management. As comprehensive care providers, pharmacists are in a unique position to develop strong patient relationships and support patients through their smoking cessation journey. Based upon regional data and provider survey, nearly $20 \%$ of patients in the James $\mathrm{Q}$. Miller MS Clinic are tobacco users. The purpose of this study was to characterize this patient population, assess knowledge about the implications of 
tobacco use on MS diagnosis and progression, assess patient interest in tobacco cessation and identify strategies for developing personalized tobacco cessation plans.

\section{Methods}

This study met exempt criteria through the UVA Health Institutional Review Board, as smoking cessation is standard of care. Eligible patients were identified by electronic medical record reporting based upon self-reported tobacco use. Beginning in June 2019, an optional 15-item survey was distributed to active tobacco users in the James Q. Miller MS Clinic during clinic visits (Appendix 1). Patients also received an educational brochure developed by the pharmacist. If the patient expressed interest in working with a clinical pharmacist for smoking cessation, the patient was then contacted by the pharmacist to begin development of a personalized cessation plan. This individualized plan included prescribing of pharmacotherapy through a collaborative practice agreement with the neurologists and nurse practitioner in the MS clinic. The pharmacist then followed and monitored at a frequency determined by the patient.

\section{Results}

A total of 29 surveys were completed during face-to-face clinic visits from June to October 2019. Demographic data is outlined in Table 1. Approximately $93 \%$ of patients started smoking prior to their diagnosis of multiple sclerosis. Interestingly, $76 \%$ of patients believed that there was no relationship between smoking and MS diagnosis and $52 \%$ were unaware of any relationship between smoking and disease progression. Less than half of patients $(41 \%)$ reported receiving counseling from a primary care physician or neurologist about the importance of smoking cessation.

In the preceding year, $58 \%$ of patients quit smoking for a duration of at least 24 hours on at least one occasion and 10\% of patients reported quitting five or more times. Eighty-six percent were considering quitting and $37 \%$ reported interest in working with a clinical pharmacist to do so. Moderate or extreme barriers to successful cessation included enjoyment of smoking (76\%) and cravings (55\%). Twenty seven percent of patients were concerned about the cost of medication and other resources, $14 \%$ of patients reported fear of failing and $10 \%$ felt there was lack of support.

Over $60 \%$ of patients reported that group classes would not be helpful for cessation and instead anticipated success with the following methods: pharmacotherapy (76\%), self-help educational materials (54\%), individual counseling via telephone (48\%) and communication via an online health portal $(44 \%)$. More patients were interested in slowly reducing the number of cigarettes per day (85\%) compared to quitting cold turkey (45\%).
Successful smoking cessation requires a multifaceted approach that includes addressing behavioral methods to reduce cravings and break habits, approaches to minimize the influence of environmental and social factors and thorough discussion about pharmacotherapeutic options. As healthcare providers, it is important to recognize and understand that smoking cessation is a highly individualized process requiring careful consideration of patient-specific factors.

\section{Conclusions}

Smoking cessation should be incorporated as a standard of care in all multiple sclerosis centers. Clinical pharmacists are in a unique position to assist in the development, implementation and monitoring of individualized smoking cessation plans. Including pharmacists on the multidisciplinary team allows them to serve as clinical extenders and dedicate additional time and resources to support patients in an individualized way. Few patients anticipate success by quitting "cold turkey", therefore smoking cessation in many cases may be a slower process that should be closely monitored with frequent communication. This frequent communication is the foundation of pharmacistpatient relationships that are essential for overcoming the inherent challenges of smoking cessation. Collaborative practice agreements, which can vary by state, afford clinical pharmacists the opportunity to closely engage in smoking cessation efforts by prescribing and adjusting pharmacotherapy for cessation. Pharmacists should be involved in discussions about the appropriateness of prescription and non-prescription pharmacotherapy and can help navigate cost and access to these therapies. This particularly engaged patient population prefers communication via telephone or health portal which lends the opportunity for clinical pharmacists to participate in telehealth. Additionally, MS teams should embrace the role of the clinical pharmacist as the patient educator. The long-term health consequences of tobacco use including cardiovascular disease and lung disease may be clear to most, but there is an apparent knowledge gap about the neurologic effects of smoking in patients with MS. Written education, such as selfhelp educational materials, should be made available to all patients and reinforced through verbal communication during clinic visits. Unlike many other factors that influence multiple sclerosis development and progression, tobacco use is one that is modifiable. It is our responsibility as healthcare providers to educate and empower patients using a personalized approach to make these positive changes. Future studies should evaluate the impact of pharmacist involvement on tobacco cessation rates in this patient population. 
Acknowledgements: The authors would like to acknowledge Meena Kannan, MD, MPH

J. Nicholas Brenton, MD, Denise Bruen, ANP-BC, MSCB and Alexandra O'Brien, RN.

Financial Disclosures: The authors have no conflicts of interest to disclose.

Funding/Support: This work was supported by the Virginia Pharmacists Association - Research and Education Foundation.

Treatment of human subjects: This study met exempt criteria through the UVA Health Institutional Review Board.

\section{References}

1. O'Gorman C, Lucas R, Taylor B. Environmental risk factors for multiple sclerosis: a review with a focus on molecular mechanisms. Int J Mol Sci.

2012;13(9):11718-11752. doi:10.3390/ijms130911718

2. Harbo HF, Gold R, Tintoré M. Sex and gender issues in multiple sclerosis. Ther Adv Neurol Disord. 2013;6(4):237-248. doi:10.1177/1756285613488434

3. Hernan MA, Olek MJ, Ascherio A. Cigarette smoking and incidence of MS. Am J Epidemiol. 2001;154(1):69-74.

4. Handel A.E., Williamson A.J., Disanto G., Dobson R., Giovannoni G., Ramagopalan S.V. (2011) Smoking and multiple sclerosis: an updated meta-analysis. PLoS ONE 6: e16149.

5. Healy BC, Ali EN, Guttmann CRG, et al. Smoking and Disease Progression in Multiple Sclerosis. Arch Neurol. 2009;66(7):858-864. doi:https://doi.org/10.1001/archneurol.2009.122 
Table 1. Patient Demographics

\begin{tabular}{|c|c|}
\hline Characteristic & $\mathrm{n}(\%)$ \\
\hline \multicolumn{2}{|l|}{ Gender } \\
\hline Female & $18(62)$ \\
\hline \multicolumn{2}{|l|}{ Age (years) } \\
\hline $26-30$ & $4(14)$ \\
\hline $31-40$ & $12(41)$ \\
\hline $41-50$ & $8(28)$ \\
\hline$>50$ & $4(14)$ \\
\hline \multicolumn{2}{|c|}{ Age at MS diagnosis } \\
\hline$<20$ & $\begin{array}{l}1(3) \\
4(14)\end{array}$ \\
\hline $21-25$ & $\begin{array}{l}4(14) \\
7(24)\end{array}$ \\
\hline $26-30$ & $5(17)$ \\
\hline $31-35$ & $1(3)$ \\
\hline $36-40$ & $3(10)$ \\
\hline $41-45$ & $0(0)$ \\
\hline $46-50$ & $2(7)$ \\
\hline $51+$ & $2(1)$ \\
\hline \multicolumn{2}{|c|}{ Number of years smoked per lifetime } \\
\hline $1-5$ & $2(7)$ \\
\hline $5-10$ & $2(7)$ \\
\hline $10-15$ & $6(21)$ \\
\hline$>15$ & $19(65)$ \\
\hline \multicolumn{2}{|c|}{ Number of cigarettes smoked per day } \\
\hline$<10$ & $9(31)$ \\
\hline $10-20$ & $12(41)$ \\
\hline $21-30$ & $5(17)$ \\
\hline $31-40$ & $2(7)$ \\
\hline
\end{tabular}


Appendix 1. Smoking Cessation Patient Survey

Name:

Demographics

Gender: $\square$ Male $\square$ Female
Age: $\square<21$
$\square 21-25$
$\square$ 26-30
$31-40$
$41-50$
$50+$

Smoking History

How many years have you been smoking?
$\square<1$
$\square 1-5$
$\square 5-10$
$10-15$
$\square 15+$

Did you start smoking before or after your MS diagnosis?

$\square$ Before $\quad \square$ After

How many cigarettes do you typically smoke during an average day?
10 or Fewer
$11-20$
$\square 21-30$
31-40
$41+$

Is there a relationship between smoking and MS diagnosis?
$\square$ Yes
$\square$ No

Is there a relationship between smoking and MS progression?

$\square$ Yes

$\square$ No

Has any healthcare provider recommended that you quit smoking?

$\square$ Yes, primary care doctor $\quad \square$ Yes, neurologist $\quad \square$ No

\section{Interest in Smoking Cessation/Quitting}

In the past year, how many times have you tried to quit smoking and stopped for at least $\mathbf{2 4}$ hours?
$\square$
$\square$
$\square 2$
$\square 3$
$\square 4 \quad \square 5+$

Are you thinking of quitting smoking?

$\square$ Yes, within 30 days $\quad \square$ Yes, within 3 months $\quad \square$ Yes, within 6 months $\quad \square$ No 
Would you like to work with a healthcare provider (clinical pharmacist) to stop smoking?
$\square$ Yes
$\square$ No
口Maybe

What are the barriers for you to quit smoking?

\begin{tabular}{|l|c|c|c|c|}
\hline & Not at all & A little & Moderate & Extremely \\
\hline Craving & 1 & 2 & 3 & 4 \\
\hline Enjoyment of Smoking & 1 & 2 & 3 & 4 \\
\hline Fear of Failure & 1 & 2 & 3 & 4 \\
\hline No Support/Too Hard & 1 & 2 & 3 & 4 \\
\hline $\begin{array}{l}\text { Cost of } \\
\text { medicine/support }\end{array}$ & 1 & 2 & 3 & 4 \\
\hline
\end{tabular}

Other:

Which method below would be of interest in helping you quit?

\begin{tabular}{|c|c|c|c|c|}
\hline & Not helpful & $\begin{array}{l}\text { Possibly } \\
\text { helpful }\end{array}$ & $\begin{array}{l}\text { Moderately } \\
\text { helpful }\end{array}$ & $\begin{array}{l}\text { Very } \\
\text { helpful }\end{array}$ \\
\hline Group quit smoking classes & 1 & 2 & 3 & 4 \\
\hline Individual counseling via phone & 1 & 2 & 3 & 4 \\
\hline Individual counseling via phone & 1 & 2 & 3 & 4 \\
\hline $\begin{array}{l}\text { Internet/MyChart information or } \\
\text { program }\end{array}$ & 1 & 2 & 3 & 4 \\
\hline Self-help educational materials & 1 & 2 & 3 & 4 \\
\hline $\begin{array}{l}\text { Reduce \# of cigarettes you smoke } \\
\text { over time until you quit }\end{array}$ & 1 & 2 & 3 & 4 \\
\hline $\begin{array}{l}\text { Stopping without any help (cold } \\
\text { turkey) }\end{array}$ & 1 & 2 & 3 & 4 \\
\hline $\begin{array}{l}\text { Medication (prescription, over the } \\
\text { counter nicotine, other) }\end{array}$ & 1 & 2 & 3 & 4 \\
\hline $\begin{array}{l}\text { Reduce \# of cigarettes over time } \\
\text { while taking medication to quit }\end{array}$ & 1 & 2 & 3 & 4 \\
\hline \multicolumn{5}{|l|}{ Other: } \\
\hline
\end{tabular}




\section{Multiple Sclerosis History}

How old were you when you were diagnosed with Multiple Sclerosis (MS)?

$$
\square<20 \quad \square 21-25 \quad \square 26-30 \quad \square 31-35 \quad \square 36-40 \quad \square 41-45 \quad \square 46-50 \quad \square 51+
$$

Which DMTs have you tried for MS? Indicate all DMTs you have ever been treated with. If not listed, please write in "Other".

\begin{tabular}{|l|l|l|}
\hline \multicolumn{1}{|c|}{ Injectable medications } & \multicolumn{1}{|c|}{ Oral Medications } & \multicolumn{1}{c|}{ Infused Medications } \\
\hline$\square \underline{\text { Avonex (interferon beta-1a) }}$ & $\square$ Aubagio (teriflunomide) & $\square \underline{\text { Lemtrada (alemtuzumab) }}$ \\
$\square \underline{\text { Betaseron (interferon beta-1b) }}$ & $\square$ Gilenya (fingolimod) & $\square \underline{\text { Novantrone (mitoxantrone) }}$ \\
$\square \underline{\text { Copaxone (glatiramer acetate) }}$ & $\square$ Mavenclad (cladrabine) & $\square \underline{\text { Ocrevus (ocrelizumab) }}$ \\
$\square \underline{\text { Extavia (interferon beta-1b) }}$ & $\square$ Mayzent (siponimod) & $\square$ Rituxan (rituximab) \\
$\square$ Glatiramer acetate & $\square$ Tecfidera (dimethyl fumarate) & $\square \underline{\text { Tysabri (natalizumab) }}$ \\
$\square \underline{\text { Glatopa (glatiramer acetate) }}$ & \\
$\square \underline{\text { Plegridy (peginterferon beta-1a) }}$ & \\
$\square \underline{\text { Rebif (interferon beta-1a) }}$ & \\
$\square \underline{\text { Zinbryta (daclizumab) }}$ & \\
\hline Other: & \\
\end{tabular}

